\title{
Principles of Design and Fabrication in Prosthodontics
}

Authors:Arnold Hohmann / Werner Hielscher

Publisher: Quintessence Publishing

Language: English

ISBN: 978-0-86715-612-6

Edition: 1/e

Publish Year: 2016

Pages: 408, illustrated

Price: $128.00 €$

"Principles of Design and Fabrication in Prosthodontics", a book written by Arnold Hohmann and Werner Hielscher covers the working steps in the design and fabrication of restoration and dentures. It is addressed to advanced dental students and technicians.

The textbook has nine chapters and describes the philosophy behind prosthodontic design, being a genuine guide. It presents the working principles and features of preprosthetics, coronal restoration, partial and removable partial dentures, telescopic and resilient anchoring and supporting elements, as well as the basic terms in the statics and dynamics of partial dentures.

There is a complex chapter dealing with complete dentures which presents most techniques of design and fabrication, such as Gysi, Hiltebrandt, Schreinmakers, Gerber, Ludwig and APFNT System. The book approaches the topic of implantology describing the implants types, the component parts, the indications and prosthodontics in implantology. After reading this book, dental technicians have the ability to carry out successful prosthodontic work much better than those who have not read it yet.

DOI: 10.25241/stomaeduj.2017.4(4).bookreview.3

Florin-Eugen

Constantinescu

DDS, PhDStudent 